Vívian Matias dos Santos

Universidade Federal de Pernambuco, Recife, PE, Brasil

\title{
Uma "perspectiva parcial" sobre ser mulher, cientista e nordestina no Brasil
}

\begin{abstract}
Resumo: Este artigo propõe compreender como mulheres cientistas estão inseridas na produção de conhecimento científico e tecnológico em universidades públicas federais específicas da Região Nordeste do Brasil. A realização de entrevistas e observações diretas nos seus cotidianos de trabalho tornaram possivel a construção de reflexões alicerçadas nas experiências sociais de mulheres cientistas pertencentes a dois grandes ramos de saberes: humanidades e as ciências supostamente "exatas". Por meio desta abordagem, situada e parcial, sobre a inserção e permanência de mulheres nas ciências contemporâneas, pudemos observar a conservação de antigas questões que ainda se colocam como prementes na compreensão feminista e de gênero das ciências.
\end{abstract}

Palavras-chave: Mulheres cientistas; gênero; ciências.

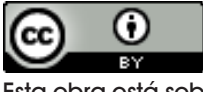

Esta obra está sob licença Creative Commons.

\section{Introdução: pontos de partida para um olhar feminista situado nas universidades nordestinas}

Como as mulheres se inserem nas ciências dos dias atuais? Como as especificidades carregadas pela produção de conhecimento científico e tecnológico nas diversas regiões do Brasil relacionam-se com a reiteração de mecanismos discriminatórios de gênero? Pensar em ciências no contexto nacional, hoje, diz respeito a pensar, também, sobre o conhecimento construído nos cotidianos institucionais das universidades. Neste artigo, propomos construir reflexões sobre como mulheres cientistas estão inseridas na produção de conhecimento científico e tecnológico em universidades específicas da Região Nordeste.

Partimos da defesa de que, no campo dos estudos sobre gênero e ciências, deve-se destacar a relevância das 
epistemologias feministas (Maria Cecília Bacellar SARDENBERG, 2002) por sua preocupação que ultrapassa a dimensão da denúncia ao sexismo nas ciências, questionando profundamente o fazer científico em suas dimensões conceituais, em seus métodos, práticas, e mais: constituindo-se como bases analítico-conceituais diversas que ampliam as possibilidades criativas de dispositivos metodológicos por meio dos quais se torna possível uma apreensão/compreensão das múltiplas discriminações no campo científico e tecnológico. Dentre as contribuições feministas, neste estudo, destacam-se como alicerces teórico-metodológicos os olhares de Sandra Harding (1993; 1996) e Donna Haraway $(1995 ; 2001)$.

Com Harding, afirmamos haver um recorrente desafio na abordagem feminista e de gênero das ciências: ultrapassar o projeto "mulheres notáveis" (1996) - que se refere ao esforço de construir um levantamento de nomes de mulheres que se destacam/destacaram na construção de conhecimentos científicos - e tomar como preocupação fundamental as múltiplas dimensões dos mecanismos discriminatórios. Neste aspecto, o presente estudo preocupa-se com os discursos e práticas que permeiam a atuação das mulheres nas ciências levando em consideração duas questões fundamentais: primeiro, as relações construídas a partir da organização social do trabalho científico; segundo, as porosidades existentes entre o cotidiano de trabalho nas instituições e as outras esferas de sociabilidade nas quais estão inseridas as cientistas, tal como a vida doméstica/familiar.

Por sua vez, Donna Haraway $(1995 ; 2001)$ proporciona uma contribuição que nos permite um alicerce consistente para as proposições de Harding $(1993 ; 1996)$ ao afirmar que: toda e qualquer ciência, todo e qualquer conhecimento científico, por ser uma construção social, deve ser "situado" em seu tempo, espaço e sujeitos.

Reconhecemos com Haraway que as ciências são formadas por uma "multiplicidade de visões", já que são constituídas por uma pluralidade de sujeitos, em distintos contextos sociais, econômicos e culturais. Deste modo, nas palavras de Haraway, "(...) apenas uma perspectiva parcial promete uma visão objetiva" (1995, p. 21). A abordagem parcial reconhece a diversidade e, portanto, complexidade das visões que compõem as ciências. Assim, é partindo desta perspectiva parcial que pensamos, aqui, a problemática participação de mulheres nas ciências.

\subsection{Situando o cenário}

Partindo deste diálogo feminista, as reflexões contidas neste artigo alicerçam-se em uma abordagem parcial e situada na realidade específica de universidades públicas 
1 De acordo com o Mapa de Investimentos do CNPq, em 2014, - Sudeste e Sul são as regiões que movimentaram maiores recursos $45 \%$ e $22 \%$, em ordem. Por outro lado, as regiões Nordeste, Norte e Centro-Oeste movimentaram $19 \%, 5 \%$ e $9 \%$ destes recursos, respectivamente.

${ }^{2}$ A ideia dos dois grandes ramos de saberes, ao invés das nove grandes áreas do conhecimento classificadas e reconhecidas oficialmente pelo CNPq, nos permite manobras reflexivas para tenta situar e perceber "distinções" ou diferenciações no fazer científico de cada uma das mulheres entrevistadas, tendo em vista a possibilidade de haver discursose práticas específicas em cada ramo de saber.

${ }^{3}$ Embora as várias áreas carreguem em si especificidades no que se referem aos seus campos de reflexão e aos seus modos de "faze ciência", defendemos que todos os conhecimentos científicos são construtos históricos e sociais e, assim, todas as ciências são sociais, inclusive as "exatas". federais nordestinas pertencentes aos estados do Ceará e Pernambuco: UFC - Universidade Federal do Ceará e UFPE Universidade Federal de Pernambuco.

Para mais bem localizar o cenário que nos rendeu as reflexões aqui esboçadas, é indispensável explicitar que estas universidades, referências empíricas de nossas análises situam-se numa região periférica no contexto científico e tecnológico nacional: no Nordeste. A Política Nacional de Ciência, Tecnologia e Inovação (CT\&l) foi construída articulandose às desigualdades socioeconômicas e culturais entre as regiões do país. Historicamente, o eixo Norte-Nordeste e Centro-Oeste representa as regiões que movimentam menores recursos financeiros em CT\&I no Brasil. ${ }^{1}$

Neste contexto de periferia científica, não é objetivo desvendar as ciências e seu processo de construção em si mesmo. O mais relevante, e objeto desta investigação, é a elaboração de uma abordagem feminista que compreenda o processo de inserção e permanência de mulheres nestes espaços acadêmicos onde são produzidos conhecimentos científicos, particularmente, em dois grandes ramos de saberes ${ }^{2}$ que consideramos estratégicos: nas humanidades, incluindo-se as ciências sociais e suas áreas aplicadas; e nas ciências supostamente "exatas", ${ }^{3}$ as quais, para esta análise, incluem áreas como engenharias e agrárias.

Por um lado, a escolha pelo campo de conhecimentos considerados "exatos" se deu de forma a tentar compreender a ałuação de mulheres cientistas em espaços onde sua presença, até hoje, ainda é pouco expressiva. Além disso, a intenção é pensar os discursos e práticas que envolvem a participação de mulheres neste ramo de saberes que, historicamente, se fez hegemônico nos marcos da modernidade das ciências ocidentais.

Os saberes "exatos" alicerçam-se, sobretudo, numa racionalidade orquestrada pelas "ideias matemáticas" que deram fundamentação paradigmática ao surgimento e consolidação de uma proposta monolítica e monocolor de "Ciência Moderna Ocidental", a qual produziu como ausentes os sujeitos (e seus saberes) que não se enquadravam nos seus parâmetros sexistas, racistas, lesbo-homo-transfóbicos, eurocêntricos e ocidentalizantes (Boaventura de Sousa SANTOS, 2006; 2010).

Inicialmente, a dita "Ciência Moderna" tinha como pretensão primeira a neutralidade, cuja condição fundamental seria a construção de conhecimento resultado de um tipo específico de racionalidade: aquela utilizada nas chamadas Hard Sciences. Neste contexto, a entrada de mulheres em muitos departamentos, tais como os de matemática, física, engenharias - nas universidades ocidentais - somente se deu já no século XX (Londa SCHIENBINGER, 2001). Os saberes 
${ }^{4} \mathrm{Na}$ UFC, foram entrevistadas $\mathrm{e}$ biografadas 3 (três) mulheres vinculadas aos Departamentos de Ciências Sociais, Física e Engenharia de Pesca. Na UFPE, foram coletados relatos orais autobiográficos de 2 (duas) mulheres pertencentes ao Departamento de Antropologia e Museologia, 1 (uma) vinculada ao Departamento de Ciência Política, e 2 (duas) atuantes no Departamento de Serviço Social. Estas mulheres foram escolhidas devido às suas performances acadêmicas reconhecidas em seus campos de estudos. ditos "exatos" representam, para os estudos de gênero e ciências, um lugar relevante para tentar compreender quais as especificidades das discriminações que permeiam o processo de construção e consolidação das carreiras científicas de mulheres em campos consolidados como espaços de predominância masculina.

Por outro lado, a seleção das humanidades ocorreu por ser neste ramo onde encontramos como objeto a vida em sociedade de uma forma geral e, particularmente, por ter sido neste espaço onde a crítica feminista e os estudos de gênero surgiram. As ciências humanas representam uma das áreas que primeiro permitiram uma entrada mais considerável de mulheres. Em termos de matrículas: "As ciências humanas no Brasil é a única área do conhecimento [predominantemente] feminina" (Neide Mayumi OSADA \& Maria Conceição COSTA, 2006 , p. 289). Todavia, neste ramo, se observado de perto, ainda se percebem alguns mecanismos sutis - ou não - de discriminação de gênero, como pudemos constatar por meio desta abordagem parcial.

\subsection{Mulheres cientistas como sujeitos}

"Não se pode imaginar saber mais do ofício do[a] cientista do que aquele[a] que pratica a ciência" (Gabriel PUGLIESE, 2007, p. 351). Então, esta proposta é elaborada a partir das experiências sociais de mulheres cientistas, obtidas por meio de entrevistas e observação direta nos departamentos ${ }^{4}$ onde constroem suas carreiras. Aqui, pensar sobre mulheres cientistas significa olhar para a lógica organizacional e ocupacional das universidades públicas federais, pensar sobre docentes e pesquisadoras doutoras - sujeitos que produzem conhecimentos científicos e tecnológicos.

Se o processo de construção da carreira das cientistas tem sido, muitas vezes, marcado pela invisibilidade - embora as mulheres sempre estivessem presentes na produção de conhecimento ao longo da história ocidental, estas foram produzidas discursivamente como ausentes, inexistentes (SANTOS, 2006) - vale explicitar que as cientistas, sujeitos desta abordagem parcial, possuem destaque e reconhecimento em seus departamentos, universidades e ramos de saberes, inseridas em redes nacionais e/ou internacionais de pesquisa. Por meio deste olhar, situado e parcial, não pretendemos edificar generalizações, pois as reflexões aqui construídas tomam como referência trajetórias de mulheres específicas, que não compõem uma amostragem estatisticamente representativa do universo de cientistas nordestinas. Para esta abordagem de base socioantropológica, o relevante não seria 'quantas', mas 'quem' daria vida a este estudo. 
Isso não nos garante ponderações aplicáveis às realidades de todas e quaisquer cientistas, mas garante uma abordagem em profundidade e parcial que reconhece a pluralidade das experiências de mulheres nas ciências.

A parcialidade deste estudo nos permitiu observar a conservação de antigas questões que ainda se colocam prementes na compreensão feminista e de gênero das ciências: as mulheres ainda encontram na conciliação/articulação entre os tempos dedicados à família e à carreira um dos obstáculos mais frequentes e dificilmente transponíveis; na composição de suas carreiras científicas, ainda se percebem discursos e práticas que reiteram a "segregação sexual territorial e hierárquica" (SCHIENBINGER, 2001); e, agravando as discriminações de gênero, emerge a condição de pertencer e atuar em universidades situadas no Nordeste, região historicamente periférica na política científica e tecnológica do país.

\section{Carreiras científicas entrecortadas por mecanismos discriminatórios}

\subsection{0 conflito permanente: família versus trabalho científico}

O peso da responsabilidade conferida pelas atividades relativas ao âmbito doméstico, familiar, ainda aparece como um dos aspectos que mais dificulta a inserção, permanência e o reconhecimento das mulheres na carreira científica. As trajetórias das mulheres entrevistadas não expressam somente dados da vida de indivíduos, mas carregam em si normas, padrões que se estabeleceram discursivamente nos contextos onde vivenciaram suas experiências.

Sem exceção, as cientistas entrevistadas percebem que, de fato, as mulheres tendem a ter menos tempo para as ciências. Elas continuam tendo que dar conta dos papéis de esposa, mãe e responsável pelo lar. Estes papéis discursivamente construídos como femininos, acarretando um acúmulo de atividades, fazem com que as cientistas tenham que construir táticas cotidianas para conseguirem ter a mesma produtividade de seus colegas do sexo masculino. Melhor dizendo, para conseguirem firmar suas carreiras científicas, as mulheres necessitam de um esforço maior do que aquele realizado por homens.

Neste âmbito, vale saber que o matrimônio no Ocidente, inserido na lógica binária da diferença sexual (masculino/ feminino), atribui assimetricamente responsabilidades e deveres para mulheres e homens. Para muitas feministas e estudiosas de gênero, o casamento significa um "contrato sexual" (Carole PATEMAN, 1993) em que aos cônjuges são 
${ }^{5}$ Cientista "E" do Departamento de Serviço Social da UFPE entrevistada durante os meses do segundo semestre de 2013. determinados comportamentos, responsabilidades diferentes e desiguais. Esta conjugalidade tem suas raízes numa sociabilidade heteronormativa (Judith BUTLER, 2010), em que o parentesco, tido como heterossexual (BUTLER, 2003), assenta os seus alicerces nas imagens simbólicas de "mãe" e "pai".

As práticas discursivas que envolvem a percepção heterossexual do parentesco estão intimamente relacionadas com o ethos que preside uma sociedade ocidental firmada sobre uma noção de "direitos e deveres" calcados em relações de dominação e subordinação. Neste sentido, podese perceber que a família tem sido "rainha e prisioneira" do social, como sugere Jacques Donzelot (1986). O discurso "familista" tem firmado normas ao mesmo tempo em que é aprisionado por estas mesmas normas.

É bem verdade que as famílias e as relações familiares têm sofrido transformações ao longo da história ocidental (Elisabeth ROUDINESCO, 2003; DONZELOT, 1986). Entretanto, ainda hoje mulheres casadas com homens têm maior dificuldade em progredir em suas carreiras, e esta realidade não é diferente para mulheres cientistas (Vivian Matias dos S. ALBUQUERQUE \& Maria Helena de P. FROTA, 2006; Vívian MATIAS DOS SANTOS, 2006).

\subsubsection{Mulheres infiéis: o tempo para a ciência como o tempo roubado da família}

O tempo para a ciência representa, muitas vezes, nas narrativas das cientistas, a negação do tempo para a família. Indo além, o tempo dedicado ao trabalho científico é percebido como o tempo que legitimamente pertence à família e, que, todavia, lhe foi roubado.

Eu gostaria de ter tido mais tempo para conviver com os meus filhos. E eu não tinha tempo porque trabalhava muito. Sempre trabalhei muito e isso significa: o trabalho formal dentro da instituição, e fora, porque para você produzir, escrever, sistematizar, planejar, você precisa de outro tempo. Então era no final de semana, noites, madrugadas. Por isso me habituei muito a trabalhar pelas madrugadas. Então isso, na verdade, te rouba tempo da tua relação com família. ${ }^{5}$

A ciência furtaria da família a presença da mãe e da esposa. Para a família conjugal heterossexual estabelecerse na carreira científica significaria um comportamento "infiel" na medida em que subverteria a prioridade que uma mulher deveria dar aos seus papéis de mãe e esposa. E, ao contrário da infidelidade do marido, no âmbito do casamento, a infidelidade da mulher é "literalmente impensável" (ROUDINESCO, 2003, p. 22). 
"Cientista "B", antropóloga do Departamento de Antropologia e Museologia da UFPE, entrevistada durante os meses do primeiro semestre de 2014
Enquanto, para mulheres cientistas, o casamento pode significar um obstáculo a mais, para homens, o casamento pode significar a construção da estrutura que dará o suporte necessário à intenção de consolidar sua carreira por meio de uma performance que lhe garanta o reconhecimento diante de seus pares concorrentes.

\subsubsection{O peso da maternidade}

A lógica em que o tempo dedicado à ciência é sentido e compreendido como o tempo roubado da família é mais profunda quando as cientistas são mães. Nas trajetórias das entrevistadas, assim como é comum na trajetória de grande parte das mulheres, a maternidade é peça fundamental para compreender as engrenagens discursivas que permeiam a dinâmica cotidiana de conciliação entre trabalho científico e família.

Em muitos estudos, a conciliação entre profissão e maternidade tem sido um dilema persistente na vida de mulheres cientistas (Attico CHASSOT, 2003; Betania MACIEL, 2004; SCHIENBINGER, 2001). Muitas mulheres optam por não terem filhos, pois percebem na maternidade um obstáculo, algumas vezes, intransponível. "Como conciliar profissão e maternidade tem sido um dos dilemas apresentados nas biografias de cientistas, artistas e literatas do século XX" (Miriam Pillar GROSSI, 2006, p. 252) e nas carreiras das cientistas sujeitos deste estudo, a maternidade não é percebida de forma diferente.

As mulheres que tem filhos de zero a quinze anos, se não tiverem um suporte de apoio, não podem fazer isso [ciência]. Não adianta! Pela forma que é dividida a educação dos filhos. Então, se o marido dela não se colocar como corresponsável, ela não poderá fazer isso. Eu, depois que me separei, não passei por isso porque minha mãe morava comigo e se disponibilizava. Eu tenho amigas que não puderam fazer doutorado fora porque optaram pela família. E, se tiver filhos, é muito pior. ${ }^{\circ}$

É frequente, nas narrativas das cientistas, a necessidade de um suporte familiar para dar conta dos cuidados indispensáveis ao desenvolvimento de filhos e filhas. Neste aspecto, percebemos que tal suporte é mais frequentemente proporcionado por outras mulheres da família, ou, mesmo, empregadas domésticas. Com pouca frequência as entrevistadas consideram que as várias atividades que envolvem a criação de filhos e filhas são equitativamente divididas com seus maridos e/ou companheiros.

Dentre as entrevistadas, duas optaram por não terem filhos. Coincidentemente ou não, as duas cientistas que 
7 Cientista "A", antropóloga do Departamento de Antropologia e Museologia da UFPE, entrevistada durante os meses do segundo semestre de 2013 e do primeiro semestre de 2014. perceberam a impossibilidade de - ou que não desejaram - maternar atuam em espaços tradicionalmente ocupados por homens: o Departamento de Física da UFC; e o Departamento de Ciência Política da UFPE. Entretanto, o fato de não serem mães não significa que estejam imunes às críticas e constrangimentos: "a falta de filhos compromete, em muitos casos, a imagem de mulher destas cientistas, colocando-as sob suspeição de anormalidade e desvio" (GROSSI, 2006, p. 252). Escolher não ter filhos, mesmo estando inseridas no contexto da heteroconjugalidade, vai de encontro à lógica de maternidade que emerge na sociedade ocidental pós-século XVIII como o destino feminino "normal", "natural" (Elisabeth BADINTER, 1985).

A glorificação da maternidade e o exagero de responsabilidades atribuídas às mães são relativamente recentes, tendo sido intensamente reforçadas apenas nos séculos XVIII e XIX. Antes disso, a criação dos filhos estava integrada a outros afazeres das mulheres, e não era considerada uma de suas principais tarefas. No contexto ocidental, a necessidade de sobrevivência na economia pré-industrial requeria, não apenas dos homens, mas, também, das mulheres, que o trabalho de produção fosse priorizado sobre as preocupações reprodutivas (Maria Lúcia ROCHA-COUTINHO, 2005, p. 122).

Nos dias atuais, nos lugares e sujeitos tomados como nossas referências, há um complexo paradoxo: as mulheres são alvos de comentários depreciativos por parte de seus pares por serem mães e por não o serem. $E$, mais grave, o processo de gravidez e maternidade, na experiência de uma cientista específica, chega a ser elemento desencadeador de escárnio ou/e assédio moral.

Na primeira reuniáo, com todo o corpo docente do curso de Antropologia e Museologia - eu tinha feito o concurso e engravidado depois e, até eu ser convocada, já estava com cinco meses de gestação [...]. Aí um colega disse: 'Estamos aqui reunidos, infelizmente aconteceu isso!'. Então, ele apontou para minha barriga. Tipo: 'Infelizmente!'. Falou como se minha gravidez fosse algo que prejudicaria o grupo. Então, tem-se uma visão bem instantânea da coisa: 'Essa professora vai passar seis meses fora?' [...] Não se leva em consideração que poderei passar trinta anos na UFPE. ${ }^{7}$

Na experiência narrada acima, nota-se que, mesmo nas humanidades, os mecanismos discriminatórios de gênero não necessariamente se dão de forma sutil. Observase, por meio desta experiência particular, que "as instituições científicas - universidades, academias e indústrias - foram estruturadas sobre a suposição de que os cientistas seriam homens com esposas em casa para cuidar deles e de suas 
${ }^{8}$ Cientista "F", socióloga do Departamento de Ciências Sociais da UFC, entrevistada durante os meses do primeiro semestre e do segundo semestre de 2011 . famílias" (SCHIENBINGER, 2001, p. 69). Isso implica pensar como as instituições científicas não são espaços apropriados para as mulheres.

As demandas específicas do contexto científico contemporâneo nos países capitalistas, no Brasil e no Nordeste, recaem de forma especificamente desgastante e desumana quando as cientistas são mulheres. Como ser esposa, mãe, docente e pesquisadora produtiva?

\subsubsection{Ser mulher e produtiva}

Assim como pode ser percebido em outros campos profissionais, permanecem, na carreira científica de mulheres, os conflitos provenientes da conciliação entre trabalho e família. Entretanto, há, no trabalho científico, uma especificidade: o tempo de permanência na universidade - salas de aula, laboratórios e demais espaços onde exercem suas funções de docentes e pesquisadoras - não é suficiente para dar conta de todas as atividades necessárias às suas produções.

Na vida das entrevistadas emerge como necessária a extensão do trabalho científico para o espaço doméstico. É trabalhando em suas casas, além do tempo de permanência nos departamentos, que estas mulheres elaboram estratégias para produzir, conforme as exigências hegemônicas no campo político-científico.

Então, assim [trabalhando em casa] eu aprendi. Às vezes meu marido diz: 'Ah! Você é muito concentrada!'. Isso porque eu aprendi a escrever ouvindo choro de menino, ouvindo telefone. Às vezes, a casa cai e eu estou escrevendo. [...] Para compensar a dispersão, eu tenho várias estratégias na minha vida. Tipo: de manhã, bem cedinho, eu amanheço com mais lucidez, aí é quando eu escrevo. [...] Quando eu estou muito cansada e atarefada [...], eu pego, por exemplo, cinco horas da manhã. Se durante uma semana você acordar todo dia às cinco, você vai ter vários escritos. Ou, quando eu não posso escrever um texto porque estou cheia de trabalho, eu escrevo assim: três linhas num dia, para não deixar morrer. É como se você aguasse uma planta. Aqui, aqui, aqui... Todo dia... Com uma semana ele está um pouquinho grande. Aí já não é folha em branco. Folha em branco é angustiante! ${ }^{8}$

Para manter performances produtivas em seus ramos de saberes, é comum as cientistas atribuírem importância às táticas e estratégias por elas elaboradas cotidianamente. Para estas mulheres, sem tais negociações estratégicas de seus tempos e das atividades executadas por seus corpos, ser produtiva e obter reconhecimento em suas carreiras significaria um feito impossível. 
" Cientista "E" do Departamento de Serviço Social da UFPE.
Destaca-se, nas narrativas das cientistas, que ser produtiva significa não somente pesquisar, mas divulgar os resultados de suas pesquisas publicando em eventos científicos, livros e, sobretudo, em periódicos reconhecidos em suas áreas. Neste sentido, a escrita aparece como um dos aspectos mais presentes em suas trajetórias científicas.

A ideia de ser produtiva está vinculada visceralmente à ideia de escrever, publicar. Publicar, por sua vez, somente é possível pela prática da pesquisa e, além disso, as pesquisas somente encontram repercussão e reconhecimento mediante a sua publicização. Ao publicarem, tornam-se conhecidas, poderão ser referências para gerações seguintes de textos publicados em seus campos de estudo (Bruno LATOUR, 2000). "Ser citada" significa um ponto articulador indispensável para suas carreiras.

Neste sentido, publicar não é um fim em si mesmo, mas um meio pelo qual pesquisas são divulgadas, tornam-se conhecidas, podendo tornar-se reconhecidas. Para as entrevistadas, este é o caminho para a consolidação de suas carreiras científicas.

Estas cientistas têm performances de alta produtividade, superando as médias brasileiras de publicação de artigos científicos em suas respectivas grandes áreas do conhecimento. Observando os seus cotidianos na universidade, alicerçando tal produtividade, percebemos haver uma intensa carga de trabalho, considerada por estas mulheres como "pesada" e até "desumana", porém, "inevitável": além das atividades de ensino no nível de graduação e/ou pósgraduação, orientando monografias, dissertações e teses, todas as cientistas entrevistadas coordenam laboratórios, grupos e/ou núcleos de pesquisa; em algum momento de suas trajetórias dedicaram-se a cargos de gestão universitária; e, com frequência, viajam para participarem de eventos científicos e firmarem parcerias com redes de pesquisa no Brasil e no exterior.

Na busca por reconhecimento e por consolidar suas carreiras, estas mulheres, em algumas de suas narrativas, deixam claro haver na lógica acadêmica das universidades públicas federais uma hierarquização entre as atividades de ensino, extensão e pesquisa. A pesquisa aparece como prioridade na política das universidades.

Na verdade, você faz um concurso para ser professor, mas o que vai te identificar, não é se você é um excelente professor, é se você é um pesquisador, se tem os títulos que universalmente, no âmbito nacional, são consagrados a um bom pesquisador. O teu referencial não é ser um docente, mas passa a ser: o pesquisador. Nessa hora, eu acho que há uma dissociação entre o ensino, a extensão e a pesquisa. ${ }^{9}$ 
Produtividade das cientistas - 2000-2014

\begin{tabular}{|c|c|c|c|c|c|c|c|c|c|}
\hline \multirow{3}{*}{\multicolumn{2}{|c|}{$\begin{array}{l}\text { MULHERES } \\
\text { CIENTISTAS } \\
\text { ÁREA }\end{array}$}} & \multicolumn{4}{|c|}{ PUBLICACCOES/ANO } & \multicolumn{4}{|c|}{ ORIENTACOOES / ANO } \\
\hline & & \multicolumn{2}{|c|}{$\begin{array}{l}\text { Artigos nacionais e } \\
\text { internacionais }\end{array}$} & \multicolumn{2}{|l|}{ Livros } & \multicolumn{2}{|l|}{ Teses } & \multicolumn{2}{|l|}{ Dissertaқ̄óes } \\
\hline & & $\begin{array}{l}\text { Cientistas } \\
\text { entrevistadas }\end{array}$ & Brasil"* & $\begin{array}{l}\text { Cientistas } \\
\text { entrevistadas }\end{array}$ & Brasil** & $\begin{array}{l}\text { Cientistas } \\
\text { entrevistadas }\end{array}$ & Brasil** & $\begin{array}{l}\begin{array}{l}\text { Cientistas } \\
\text { entrevistadas }\end{array} \\
\end{array}$ & Brasil** \\
\hline \multirow{6}{*}{$\begin{array}{l}\mathrm{H} \\
\mathrm{U} \\
\mathrm{M} \\
\mathrm{A} \\
\mathrm{N} \\
\mathrm{I} \\
\mathrm{D} \\
\mathrm{A} \\
\mathrm{D} \\
\mathrm{E} \\
\mathrm{S} \\
\end{array}$} & $\begin{array}{l}\text { A / } \\
\text { Antropologia }\end{array}$ & 0,91 & 0,50 & 0 & 0,13 & 0 & 0,14 & 0 & 0,45 \\
\hline & $\begin{array}{l}\text { B } \\
\text { Ancropologia }\end{array}$ & 0,92 & 0,50 & 0,07 & 0,13 & 0 & 0,14 & 0,92 & 0,45 \\
\hline & $\begin{array}{l}\text { C } ? \\
\text { Ciência } \\
\text { Politica } \\
\end{array}$ & 0,35 & 0,50 & 0,78 & 0,13 & 0 & 0,14 & 1,00 & 0,45 \\
\hline & \begin{tabular}{|l|} 
D I \\
Serviço \\
Social \\
\end{tabular} & 0,64 & 0,47 & 1,00 & 0,13 & 1,78 & 0,00 & 2,30 & 0,56 \\
\hline & $\begin{array}{l}\text { El } \\
\text { Servico } \\
\text { Social } \\
\end{array}$ & 0,60 & 0,47 & 0,07 & 0,13 & 0 & 0,09 & 0 & 0,56 \\
\hline & $\begin{array}{l}\text { F/ } \\
\text { Sociologia }\end{array}$ & 2,21 & 0,50 & 0,57 & 0,13 & 1.57 & 0,14 & 1.28 & 0,45 \\
\hline $\begin{array}{l}E \\
X \\
A \\
T\end{array}$ & $\begin{array}{l}\text { G ! } \\
\text { Engenharia } \\
\text { de Pesca }\end{array}$ & 9,14 & 0,99 & 0,57 & 0,05 & 1,62 & 0,13 & 2,07 & 0,38 \\
\hline $\begin{array}{l}\mathrm{A} \\
\mathrm{S} \\
\mathrm{H}\end{array}$ & H/Fisica & 0,92 & 0,85 & 0 & 0,07 & 0,50 & 0,11 & 0,78 & 0,28 \\
\hline \multicolumn{2}{|c|}{$\begin{array}{l}\text { TOTAL } \\
\text { (Soma das } \\
\text { médias) }\end{array}$} & 15,69 & 4,78 & 3,06 & 0,9 & 5,47 & 0,98 & 8,35 & 3,58 \\
\hline
\end{tabular}

Fonte: Elaboração nossa por meio dos currículos das cientistas entrevistadas, disponíveis na Plataforma Lattes - CNPq.

* Classificação referente aos ramos de saberes considerados estratégicos para esse estudo.

** Referente à média de produtividade de pesquisadores e pesquisadoras, no Brasil, nas respectivas grandes áreas do conhecimento das cientistas entrevistadas. Elaboração por meio de dados fornecidos pelo Diretório de Grupos de Pesquisa no Brasil - Lattes/CNPq (2000 a 2014).

${ }^{10}$ Cientista "G" do Departamento de Engenharia de Pesca da UFC, entrevistada durante os meses do primeiro e segundo semestres de 2011
Embora as cientistas entrevistadas sejam produtivas, constroem críticas veementes ao produtivismo, cuja palavra de ordem é "publicar, publicar e publicar!" 10 em detrimento das atividades de ensino e extensão.

Por meio dos olhares das cientistas, percebemos que a lógica produtivista é compreendida como algo contemporâneo, novo, e que há, intrínseco ao disciplinamento necessário aos padrões de produtividade, um processo de proletarização do trabalho científico.

Hoje em dia o tempo se inseriu no nosso trabalho. Antes a gente associava o tempo ao trabalho do operário. O operário era aquele que tinha o tempo como um elemento, quase de escravização do seu trabalho. Marx relata isso lindamente na sua obra. [...] E hoje nós temos o tempo de trabalho que talvez não 
1 Cientista "F", socióloga do Departamento de Ciências Sociais da UFC.
${ }^{12}$ Elaboração nossa por meio do entrecruzamento dos dados fornecidos pelo Diretório dos Grupos de Pesquisa no Brasil e Fomento do CNPq (2000-2014) e das informações provenientes dos currículos lattes das docentes pesquisadoras.

\begin{abstract}
chegue a ser uma "mais-valia", mas é uma "mais qualquer coisa". Alguém vai ter que discutir o que é esse trabalho que se carrega no corpo. Que você tem que ir para casa e ficar espremido por esse tempo e por essa necessidade absoluta de permanente grau de crescimento que nós temos. ${ }^{11}$
\end{abstract}

Esta sensação de controle do tempo, dos corpos e do que se produz não se trata de uma questão presente somente nas realidades dos departamentos aos quais as cientistas entrevistadas são vinculadas, conforme afirma Santos:

Por um lado, a comunidade científica estratificou-se, as relações de poder entre cientistas tornaram-se mais autoritárias e desiguais e a esmagadora maioria dos cientistas foi submetida a um processo de proletarização no interior dos laboratórios e dos centros de investigação. Por outro lado, a investigação capitalintensiva (assente em instrumentos caros e raros) tornou impossível o livre acesso ao equipamento, o que contribuiu para o aprofundamento do fosso, em termos de desenvolvimento científico e tecnológico, entre países centrais e países periféricos (2005, p. 57).

Trata-se de um processo amplo que acompanha o desenvolvimento das sociedades capitalistas, embora em cada lugar isso se dê de formas particulares. E, no caso das universidades do Nordeste brasileiro, a proletarização é percebida como intensificada, conforme será discutido mais adiante.

\subsubsection{Acesso desigual aos recursos em CT\&l}

Devido à sobrecarga de trabalho - doméstico e científico -, e não por serem menos qualificadas, de forma geral, as mulheres tendem a publicar menos (MATIAS DOS SANTOS, 2012). Todavia, as cientistas entrevistadas chegam a ter uma média de publicação anual entre 8,15 e 0,07 pontos acima da média nacional de publicação ${ }^{12}$ de artigos em suas respectivas grandes áreas.

Mesmo sendo mais produtivas que a média de pesquisadores/as no Brasil, suas produtividades não são constantes: no período em que os filhos são pequenos, suas produtividades tendem a declinar. Cuidando das crianças, as mulheres publicam menos e participam de eventos científicos com menor frequência.

Na conflituosa conciliação entre o tempo para a família e para o trabalho, estas cientistas acabam tendo menos tempo para as ciências se comparadas aos seus pares do sexo masculino. Isso repercute no acesso desigual aos recursos destinados à produção de conhecimentos: as mulheres 
${ }^{13}$ Cientista "H" do Departamento de Física da UFC, entrevistada durante os meses do segundo semestre de 2010 e primeiro semestre de 2011.
14 Historicamente, as principais instituições deliberativas e de fomento no Brasil representam lugares "feitos por homens e para homens". Como exemplo, temos o caso do CNPq, principal agência de fomento à pesquisa no país, que se constituiu como espaço ocupado - principalmente em cargos decisórios - por homens (MATIAS DOS SANTOS, 2012).

${ }^{15}$ Cientista "D" do Departamento de Serviço Social da UFPE, entrevistada no mês de outubro de 2014 tendem a movimentar menores recursos com suas pesquisas (MATIAS DOS SANTOS, 2012).

Sabendo que "a luta mais importante no seio da comunidade científica é a luta pela utilização dos investimentos públicos e privados" (SANTOS, 1978, p. 41), por que as mulheres movimentam menores recursos? Que mecanismos se estabelecem para que seus projetos sejam mais 'baratos' que os de seus colegas homens? Neste aspecto, a fala de uma cientista suscitou-nos reflexões esclarecedoras:

Suspeito que um pesquisador solicita recursos para executar projetos de acordo com a sua disponibilidade de tempo. E, como as mulheres têm que dar conta de várias outras atividades em seu cotidiano, tal como sua vida familiar, elas pedem menores recursos para projetos menores, visto que seu tempo é reduzido para a ciência. ${ }^{13}$

Aparentemente, a constatação preocupante de que as mulheres acessam menores recursos da política de fomento à pesquisa está intrinsecamente vinculada ao fato de as mulheres terem menos tempo para as ciências. Isso implica pensar que não poderemos compreender as desigualdades de gênero no campo científico sem olhar, também, para o cotidiano dessas mulheres fora das universidades, em seus lares, com as suas famílias.

\subsection{Segregação sexual territorlal hierárquica}

No Brasil, não somente nas universidades, mas no contexto da Políitica de CT\&I Nacional, ainda há uma explícita segregação sexual territorial (divisão sexual das áreas de conhecimento) agravada pela segregação sexual hierárquica (SCHIENBINGER, 2001): em todas as áreas, as mulheres ainda encontram maiores dificuldades para ocupar cargos de prestígio nas universidades, bem como continuam pouco expressivas nos cargos decisórios da política científica e tecnológica nacional. ${ }^{14}$

Referindo-se às que serviram como referência para este estudo, temos universidades em que, durante toda a sua existência, jamais uma mulher ocupou a reitoria. Segundo as narrativas das cientistas, as mulheres têm maiores dificuldades em se inserirem nos cargos mais elevados da gestão institucional, em acumular "capital científico-político" (Pierre BOURDIEU, 2004). Isso pode ser constatado na seguinte fala: ${ }^{15}$ "Quando eu fui pró-reitora eu me destaquei, então fizeram uma manobra política para que eu não lançasse candidatura para a reitoria. Todas as chapas que saíram eram lideradas por homens".

Na realidade dos departamentos destas cientistas, a segregação sexual territorial e hierárquica parece ser um 


\begin{abstract}
${ }^{16}$ Neste sentido, um trecho do diário de campo construído por ocasião do primeiro contato com - Departamento de Física da UFPE faz-nos perceber a "naturalização" da ideia que afirma as ciências ditas "exatas", no caso, a Física, como um lugar para homens. Segue: "Eu não sabia onde se localizava este Centro de Ciências Exatas no interior do campus de Recife e por isso resolvi pedir informação a um rapaz que passou pelo caminho. Por sorte, ele afirmou que estava indo para o mesmo local, então fomos juntos, caminhando. Nesta oportunidade ele questionou sobre o que eu desejava no Centro e sobre o que eu pesquisava, então explique que eu não era pertencente àquele Centro e que estava desenvolvendo uma pesquisa sobre a inserção de mulheres na ciência, que buscava entender questões como: por que o número de mulheres no curso de Física é tão reduzido? Prontamente aquele estudante de doutorado em Química me respondeu: 'Mas isso é obvio, mulheres não estudam física por que física é difícil!"”.
\end{abstract}

dos mecanismos mais explícitos e presentes, capazes de continuar reiterando discursos e práticas discriminatórias.

\subsubsection{Lugares para homens ou para mulheres? As consequências da transgressão das fronteiras}

Há uma intensificação dos mecanismos discriminatórios de gênero quando a luta cotidiana por consolidação da carreira das cientistas se dá em áreas tradicionalmente masculinas. A lógica sexista parece permanecer na organização social do trabalho científico (HARDING, 1996) nas diversas áreas do conhecimento, no seio dos distintos ramos de saberes.

Olhar para o ramo de saberes dito "exato" nos remete à reflexão sobre espaços científicos ocupados tradicionalmente por homens. ${ }^{16} \mathrm{Em}$ contrapartida, pensar nas humanidades, frequentemente, faz emergir a (pré)noção de que este ramo de saberes é o mais equitativo do ponto de vista das relações de gênero. Entretanto, as narrativas das cientistas nos mostram que, mesmo em departamentos em que a presença de homens e mulheres se dá numericamente equilibrada, isso não implica a ausência de práticas discriminatórias.

E, ainda, no seio das humanidades, podemos encontrar campos de estudos e disciplinas permeadas pela lógica da divisão sexual do conhecimento, como, por exemplo, o caso da Ciência Política que emerge nas ciências sociais construída como uma disciplina tradicionalmente masculina.

Especificamente, o Departamento de Ciência Política estudado é um espaço de predominância masculina: dos 17 docentes efetivos do Departamento, apenas 3 (três) são mulheres. Neste sentido, pudemos perceber, mais uma vez, que também no seio das ciências sociais opera a lógica da segregação sexual territorial e hierárquica. Como isso acontece? Sabendo-se que a inserção das mulheres no campo político, no Brasil, se dá de forma desigual, haveria um reflexo desta questão no que se refere ao interesse de mulheres pesquisadoras por problemáticas relativas à política?

De acordo com Miriam Pillar Grossi e Sônia Malheiros Miguel (2001), ainda parece haver, no Brasil, um processo que constrói os cargos políticos como lugares a serem ocupados por homens. Em seu texto, as autoras citam uma entrevista realizada com uma Deputada Estadual de São Paulo, que afirma: "Espera-se que as mulheres façam o dobro dos homens, na metade do tempo e sem mérito algum [...]. Acho que isso marca muito o nosso trabalho" (GROSSI \& MIGUEL, 2001, p. 181).

Dentro das ciências eu acho que a ciência política é a mais masculina, na verdade. Comparando não só com

814 Estudos Feministas, Florianópolis, 24(3): 801-824, setembro-dezembro/2016 
${ }^{17}$ Cientista "C" do Departamento de Ciência Política da UFPE, entrevistada no mês de março de 2014.

${ }^{18}$ Cientista "C" do Departamento de Ciência Política da UFPE. o departamento da UFPE, mas com o departamento de outras universidades, isso é bastante comum: a gente ter um departamento composto quase $100 \%$ por homens. Isso acaba se reproduzindo. Tanto é que aqui na UFPE acho que a primeira professora mulher foi aparecer com três anos atrás [...]. É um pouco complicado para você se inserir dentro do departamento. E também, em relação aos alunos, você sempre tem essa limitação: pelo fato de você ser mulher já deve ter certo cuidado. E no meu caso, como sendo uma mulher mais nova, se torna mais complicado um pouquinho. Você não é vista como pesquisadora, como professora. Você na verdade é sempre vista como a monitora, né? Então isso é bastante comum aqui. ${ }^{17}$

Com esta narrativa, parece que a ciência política, seguindo uma tradição, se estabelece como uma área não somente de predominância numérica masculina, mas como uma área em que, para conseguirem reconhecimento, as mulheres enfrentam maiores obstáculos do que aqueles enfrentados por mulheres atuantes em áreas que não têm predominância de homens. Entretanto, esta possível discriminação aparenta não existir. Seria uma discriminação "velada". Para a cientista "C", fica evidente que o fato de ser uma mulher, em um departamento de maioria masculina, acarreta alguns tensionamentos no trabalho:

Eu acho que a discriminação que existe é muito mais velada. É muito mais inconsciente, certo? Em alguns sentidos você tem uma preocupação: 'Não, não vamos falar isso porque ela está aqui, ela não pode ouvir!', ou, 'Não vamos pedir para ela fazer tal coisa porque isso não é atividade de mulher', ou, 'Não vamos deixar ela sozinha com os alunos porque pode pegar mal!'. Então, tem assim, alguma coisa mais inconsciente. Na verdade, os próprios professores nem notam que estão tendo esse tipo de comportamento. ${ }^{18}$

Esta narrativa nos fez perceber que as situações em que se sentiu discriminada revelaram-se alicerçadas por duas dimensões principais: a suposta incapacidade feminina para certos assuntos; e a percepção das mulheres como objetos do desejo sexual dos homens.

A primeira dimensão destas práticas discriminatórias diz respeito à crença numa suposta incapacidade feminina para a execução de determinadas atividades. Ao ouvir de seus pares do sexo masculino frases do tipo "Não vamos pedir para ela fazer tal coisa porque isso não é atividade de mulher", a cientista sente-se tolhida da possibilidade de participar efetivamente das diversas atividades e dos distintos espaços do Departamento.

A segunda dimensão é a percepção das mulheres como objetos dos desejos sexuais dos homens do Departamento: 
${ }^{19}$ Cientista "D" do Departamento de Serviço Social da UFPE.

${ }^{20}$ Cientista "D" do Departamento de Serviço Social da UFPE. alunos e docentes. A ideia recorrente expressa na frase "Não vamos deixar ela sozinha com os alunos porque pode pegar mal!" pode significar, na execução das atividades cotidianas, uma forte vigilância sobre o corpo e a sexualidade feminina. O discurso ambíguo onde os docentes, aparentemente, estão tentando proteger a reputação da colega, traduz-se como um dos mais potentes entraves para a conquista de espaço, de reconhecimento de seu trabalho.

Por outro lado, as dificuldades que as mulheres enfrentam em áreas de predomínio masculino não parecem ser vivenciadas por homens atuantes em carreiras tradicionalmente femininas:

Durante minha carreira de 30 anos no Departamento de Serviço Social, acho que nunca vi um homem ter mais dificuldades que as mulheres. Ao contrário percebo que a competição é estabelecida entre as mulheres, como se os homens ficassem fora da disputa. Os homens - que são minoria - são bem recebidos, acolhidos. Eu diria, até, que são cuidados e protegidos pelas colegas. Facilmente os homens atuantes no Serviço Social conseguem um lugar de destaque. ${ }^{19}$

Sendo o Serviço Social um espaço tradicionalmente ocupado por mulheres, na UFPE, poucos foram os homens que atuaram como docentes nesta área. Entretanto, segundo as narrativas da cientista acima citada, mesmo sendo minoria numérica neste espaço, isso não significou uma condição de subalternidade no Departamento. "Eles são minoria, mas terminam desenvolvendo um relacionamento muito afetuoso com as mulheres. [...] A concorrência se dá entre as próprias mulheres. Os homens são enaltecidos". ${ }^{20}$

Esta fala explicita uma questão complexa no âmbito da discriminação de gênero nas ciências: por meio desta e de outras pesquisas anteriores, sabemos que, em uma mão, há uma difícil inserção e consolidação da carreira de mulheres cientistas em áreas tradicionalmente masculinas, como na Física, por exemplo; em outra, isso parece não ocorrer com homens atuantes em carreiras construídas historicamente como femininas. Esta problemática nos fez perceber que, para compreender a complexidade pela qual os mecanismos discriminatórios incidem sobre as carreiras das mulheres cientistas, emergem como necessários estudos que abordem, também, a presença de homens em espaços de predominância feminina.

\section{3 "Humanidades" e "exatas": fazeres distintos?}

Observando os fazeres das cientistas em seus ramos de saberes, pudemos reafirmar que todos os conhecimentos,

816 Estudos Feministas, Florianópolis, 24(3): 801-824, setembro-dezembro/2016 
inclusive os ditos "exatos", são socialmente construídos: é indispensável o diálogo com estudos produzidos por outros/ as pesquisadores/as anteriormente e em outros lugares, inserindo as cientistas em "linhagens" (Mariza PEIRANO, 1995) acadêmicas; ao mesmo tempo, tais conhecimentos são socializados por meio do processo de orientação de estudantes, garantindo-se descendentes. Assim é assegurada a perenidade das ideias.

Neste aspecto, sobressaiu-se outro ponto comum importante: tanto nas humanas quanto nas "exatas", posicionar-se teoricamente demarca a posição das cientistas em seus departamentos: as disputas teóricas traduzem-se como disputas políticas no seio da comunidade científica.

Por outro lado, mesmo identificando alicerces comuns, por meio dos fazeres das cientistas, percebemos nos ramos de saberes elementos de diferenciação, tanto no que se referem às performances científicas, quanto aos aspectos objetivos/ estruturais que envolvem a produção de conhecimentos.

Nas performances científicas das entrevistadas percebemos: primeiro: nas "exatas", as cientistas dedicam maior quantidade de horas aos laboratórios, executando e coordenando experimentos, enquanto nas humanas as incursões em campo são percebidas como aquilo que demanda um tempo significativo; segundo: nas "exatas", as características da organização do trabalho promovem a prática mais intensa de publicação em coautorias, já que diversos pesquisadores/as e estudantes participam das várias etapas procedimentais dos experimentos. Copartícipes são potenciais coautore/as.

Vale dizer que as cientistas, nas humanas e sociais aplicadas, reconhecem como necessário um deslocamento para "estar fora em contato com o outro" e, paradoxalmente, na construção de saberes e nas suas escritas explicitam como relevante certo isolamento, sendo frequente a ideia da produção científica como um processo solitário. Esta dimensão torna-se reafirmada ao analisarmos as "redes de colaboração" nos currículos lattes das cientistas: enquanto, nas humanas, observamos uma presença média de 3 (três) coautorias, nas "exatas", identificamos uma média de 52,5 coautorias.

Referindo-se aos aspectos objetivos/estruturais que perpassam tais performances científicas, percebemos que os projetos de pesquisa das cientistas atuantes nas "exatas" movimentam maiores recursos, bem como os laboratórios por elas coordenados necessitam de um investimento financeiro consideravelmente maior em equipamentos. A relevância do acesso aos recursos para aquisição de equipamentos é ressaltada pelas cientistas na física e na engenharia. $O$ fato de possuir ou não determinados equipamentos, máquinas e 


\begin{abstract}
${ }^{21}$ Analisar a distribuição de Bolsas de Produtividade significa analisar como se estabelecem as hierarquias entre pesquisadores/as das diversas regiões na política científica nacional. Neste âmbito, percebe-se a liderança do eixo Sudeste-Sul, detentor de $81 \%$ das Bolsas de Produtividade, enquanto que o Nordeste, Norte e CentroOeste, juntos, possuem apenas $19 \%$ destas bolsas (Mapa de Investimentos do CNPq, 2014).
\end{abstract}

materiais em geral repercute diretamente nas possibilidades de produção de conhecimento de um grupo, bem como nas condições de reconhecimento no seio da comunidade científica (Bruno LATOUR \& Steve WOOLGAR, 1997).

Nas universidades analisadas, em 2014, os ramos de saberes "exatos" - que nesta abordagem agregam as Exatas e da Terra, Agrárias, Engenharias e Computação - foram contemplados com $64 \%$ e $62 \%$ dos recursos destinados ao apoio à pesquisa pelo CNPq (2014) na UFPE e UFC, respectivamente. Já as humanidades - somando as Humanas e Sociais Aplicadas - não ultrapassaram a captação de 5\% dos recursos nas duas universidades.

Como um reflexo da política científica nacional, nas universidades onde as cientistas, sujeitos deste estudo, tecem suas carreiras, observa-se a hegemonia dos saberes "exatos" em termos capital-intensivos. E, considerando que é neste ramo onde se encontra maior parte das áreas de predominância masculina, como as mulheres poderiam ter acesso igualitário aos recursos destinados à pesquisa?

\section{3 Últimas considerações: sobre a inter- seccionalidade das discriminações}

\subsection{Gênero, geração e pertencimento regional}

Historicamente, o desenvolvimento capitalista no Brasil se deu de forma desigual entre as distintas regiões. Sudeste e Sul protagonizaram o processo de industrialização e urbanização do país e, acompanhando este desenvolvimento desigual, também se construiu a política científica nacional. ${ }^{21}$

Olhar para a realidade específica destas universidades nordestinas fez-nos perceber uma questão relevante: embora estas universidades não tenham acesso aos mesmos recursos e não disponham de infraestruturas semelhantes às das universidades do eixo Sudeste-Sul, há uma cobrança por produtividade baseada nos parâmetros daquelas instituições - que lideram a produção científica e tecnológica no país.

A cobrança por alta produtividade em um contexto de condições de trabalho precárias atinge todas/os as/os docentes e pesquisadores/as, independente de seu sexo e identidade de gênero. Todavia, atinge homens e mulheres de formas distintas.

Por meio das experiências das cientistas, percebemos que, na composição de suas carreiras, permeia uma dupla discriminação: ser mulher e nordestina no campo científico brasileiro. As desigualdades regionais que marcam historicamente a Política de CT\&l no Brasil são percebidas pelas mulheres entrevistadas como definidoras e limitantes em suas carreiras. 
${ }^{22}$ Cientista "C" do Departamento de Ciência Política da UFPE.
Difícil!... Bastante difícil!... Na verdade, a gente tem uma série de limitações para desenvolver ciência no Brasil. E, especificamente em Pernambuco, e especificamente como mulher, que se torna um pouco mais difícil. [...] Principalmente na área de ciência política, porque a gente está falando de uma área tradicionalmente masculina, tradicionalmente Sudeste. Então, às vezes, a gente tem pouca inserção, pouco acesso a certas discussões também por uma limitação já inicial. Mesmo que a gente tenha qualificação para fazer algumas atividades, a gente tem várias dificuldades para fazer, principalmente aqui. [...] Eu acho que a principal limitação é de infraestrutura e de recursos. ${ }^{22}$

Segundo a cientista "B", do Departamento de Antropologia e Museologia da UFPE, há um "espírito de colonizado" que assombra os/as docentes, que, apesar de criticarem os parâmetros estipulados pelo eixo sudeste-sul, batalham para se adequar a estes, abrindo mão de sua autonomia e reforçando/legitimando as desigualdades regionais na política científica.

Indo além, tivemos como sujeitos deste estudo mulheres pertencentes a distintas gerações de cientistas - desde mulheres com menos de 10 anos de carreira até mulheres com 30 anos de atuação acadêmica. Conhecer as trajetórias destas mulheres pertencentes a distintas gerações possibilitou-nos notar que, se agregando à dupla discriminação - de gênero e regional - destacam-se, nos departamentos analisados, ainda, desigualdades geracionais.

As desigualdades geracionais ocorrem de forma contraditória: se, por um lado, os critérios de produtividade - intensificados a partir dos anos 1980/1990 no Brasil - são mais bem assimilados nos ritmos de trabalho de jovens pesquisadoras, por outro, observa-se que pesquisadoras em início de carreira inserem-se de forma mais precária nos contextos dos departamentos analisados.

As entrevistadas, ao narrarem os cotidianos de trabalho em seus Departamentos, proporcionaram-nos a percepção das seguintes questões sobre mulheres em início de carreira científica: 1) quando não são doutoras - não podem concorrer aos editais de apoio a projetos de pesquisa, nem podem pleitear bolsas de iniciação científica -, as pesquisas são executadas de forma precária, as quais, sem o auxílio de bolsistas, tornam-se sobrecarga de trabalho. Na mesma medida, acabam sendo executadas de forma limitada, com recursos próprios, uma vez que não houve financiamento institucional para o seu desenvolvimento; 2) quando são contratadas temporariamente, a exemplo do cargo de professor/a substituto/a, mesmo participando de grupos de pesquisa consolidados, devem dedicar-se exclusivamente 
${ }^{23}$ Cientista "B" do Departamento de Antropologia e Museologia da UFPE.

\footnotetext{
${ }^{24}$ Compreendemos por cientistas que possuem destaque aquelas que lideram laboratórios, núcleos e/ou grupos de pesquisa inseridos em redes de pesquisa nacional e/ou internacional, que possuem uma média de produtividade (publicações) acima da média de seus pares em suas respectivas áreas, podendo ser bolsistas de produtividade do CNPq.
}

ao ensino de graduação, sendo-lhes subtraídas a pesquisa e a extensão.

Por outro lado, paradoxalmente, algumas mulheres reconhecem que as exigências produtivistas no cenário científico, refletidas nas universidades como supervalorização das atividades de pesquisa e desvalorização do ensino e extensão, se dão permeadas, também, por discriminações geracionais, tendo em vista que o ritmo de produção daqueles e daquelas que já estão nas universidades há mais de duas décadas não é o mesmo dos/as jovens recémingressos/as.

Essa política é burra, é idiota! Um Departamento não se faz só de publicações, tem várias outras questóes que precisam ser feitas. Como é que você não pontua o ensino, a produção técnica? Ela é uma política estúpida e extremamente neoliberal! Ela é massacrante, desumana! E ela desconsidera as pessoas mais velhas, que não foram formadas nesse perfil. ${ }^{23}$

\subsection{Quem são as cientistas que se destacam? Mulheres cis, brancas, heterossexuais, pertencentes à classe média}

As cientistas entrevistadas são mulheres pertencentes aos dois ramos de saberes - humanidades e "exatas" -, atuantes nas universidades nordestinas selecionadas, que possuem destaque em seus departamentos, em seus campos de estudos - este foi o critério inicial de inclusão destes sujeitos nesta pesquisa. ${ }^{24}$ Neste âmbito, emerge uma das lacunas deste estudo: não tomamos como condição para inclusão de sujeitos os marcadores de raça/etnia, trans* identidades de gênero, orientação sexual e classe social.

Contudo, mesmo não partindo destas questões, no decorrer da pesquisa, notamos um perfil comum às mulheres entrevistadas. Ao buscarmos cientistas reconhecidas em seus ramos de saberes, quem encontramos? Nos meandros de suas identidades cisgênero, encontramos mulheres brancas, heterossexuais, provenientes de classe média. Deste modo, após a conclusão deste estudo, emergiram muitos questionamentos, dentre eles: $E$ se as mulheres nordestinas, sujeitos deste estudo, fossem negras, indígenas, bissexuais, lésbicas ou transgêneros? Como se daria as suas inserções na carreira científica? Que outros discursos e práticas discriminatórias permeariam suas trajetórias nas ciências, nas universidades?

Estes questionamentos explicitam que as reflexões aqui contidas tratam-se de uma "visão parcial" sobre mulheres cis, brancas, heterossexuais e de classe média em universidades nordestinas públicas federais específicas. $\mathrm{E}$, reconhecendo a sua parcialidade, acreditamos que esta é 
uma discussão inacabada, não havendo, aqui, a pretensão de edificarmos generalizações.

Destaca-se, então, a relevância da realização de pesquisas nas diversas regiões e em cada estado brasileiro que contemplem as desigualdades em suas "interseccionalidades" (Adriana PISCITELLI, 2008) como modo de consolidarmos as diversas abordagens feministas. É inquestionável haver uma articulação entre as diversas discriminações. Ao gênero, articulam-se as discriminações de raça (Kimberlé CRENSHAW, 2002) e etnicidade, geracionais, lesbo-homotransfóbicas, classistas (HARDING, 1996; Danièle KERGOAT, 2010) e relativas ao pertencimento territorial. Há uma necessidade de construção de outras várias abordagens parciais e interseccionais que nos proporcionem conhecer a participação de mulheres nas ciências no país em sua pluralidade e complexidade.

Portanto, apostamos que, para entendermos com maior profundidade a problemática participação de mulheres nas ciências no Brasil, tem-se que apostar na vantagem epistemológica das abordagens parciais, como defende Haraway (2001), no esforço de situar as mulheres cientistas e os conhecimentos por elas produzidos nas especificidades de seus tempos, espaços, condições objetivas e subjetivas.

No Brasil, observamos avanços nos estudos sobre a participação de mulheres no âmbito da pesquisa financiada pelas agências nacionais, principalmente no que diz respeito à participação feminina na concessão de recursos pelo CNPq (Hildete Pereira MELO \& Helena Maria M. LASTRES, 2006). Todavia, ainda está por ser conhecida a atuação de mulheres na pesquisa financiada pelas diversas fundações estaduais. Também nos cabe o esforço em desvendar as particularidades das práticas e discursos que permeiam a inserção e permanência de mulheres cientistas nos diversos institutos de pesquisa, nas universidades privadas e públicas, federais e estaduais.

No campo dos estudos de gênero e feministas das ciências, muito trabalho ainda teremos pela frente!

\section{Referências}

ALBUQUERQUE, Vivian Matias; FROTA, Maria Helena de Paula. "Na penumbra da ciência". O Público e o Privado, v. 1, n. 8, p. 87-107, jun./dez. 2006.

BADINTER, Elisabeth. Um amor conquistado: O mito do amor materno. Rio de Janeiro: Nova Fronteira, 1985.

BOURDIEU, Pierre. Os usos sociais da ciência: por uma sociologia clínica do campo científico. São Paulo: UNESP, 2004.

BUTLER, Judith. "Corpos que pesam: sobre os limites discursivos do sexo". In: LOURO, Guacira Lopes (Org.). O corpo educado 
- pedagogias da sexualidade. Belo Horizonte: Autêntica, 2010. p. 151-172.

"O parentesco é sempre tido como heterossexual?". Cadernos Pagu, n. 21, p. 219-260, 2003.

CHASSOT, Attico I. A Ciência é masculina? É, sim senhora! São Leopoldo: UNISINOS, 2003.

CNPq. "Painel de investimentos". Brasil, 2014. Disponível em: http://www.cnpq.br/painel-de-investimentos.

CRENSHAW, Kimberlé. "Documento para o Encontro de Especialistas em Aspectos da Discriminação Racial Relativos ao Gênero". Revista Estudos Feministas, Florianópolis, v. 10, n. 1, p. 171-188, jan./jun. 2002.

CURRÍCULO Lattes. Plataforma Lattes - CNPq. Brasil, 2014. Disponível em: http://lattes.cnpq.br/.

DIRETÓRIO de Grupos de Pesquisa no Brasil. "Produção C,T\&A: Produção e produtividade C, T e A dos pesquisadores doutores segundo o tipo de produção e a grande área do conhecimento predominante nas atividades do grupo". Plataforma Lattes/CNPq (2000 a 2014). Disponível em: http://lattes.cnpq.br/web/dgp/producao-c-t-a. Acesso em: 11 dez. 2015.

DONZELOT, Jacques. Polícia das Famílias. Rio de Janeiro: Graal, 1986.

GROSSI, Miriam Pillar. "Duas Germaines e uma Denise: alunas de Mauss". In: GROSSI, Miriam Pillar et al. (Orgs.). Antropologia Francesa no século XX. Recife: Fundação Joaquim Nabuco; Massagana, 2006. p. 239-258.

GROSSI, Miriam Pillar; MIGUEL, Sônia Malheiros. "Mulheres na política, mulheres no poder". Revista Estudos Feministas, Florianópolis, v. 9, n. 1, p. 164-167, jan./jul. 2001.

HARAWAY, Donna. "Saberes localizados: a questão da ciência para o feminismo e o privilégio da perspectiva parcial". Cadernos Pagu, Campinas, n. 5, p. 07-41, 1995.

"Situated Knowledge: the science question in feminism and the privilege of partial perspective". In: LEDERMAN, Muriel; BARTSCH, Ingrid. The gender and science reader. London/New York: Routledge, 2001 . p. 169-188.

HARDING, Sandra. "A instabilidade das categorias analíticas na teoria feminista". Revista Estudos Feministas, Florianópolis, n. 1, p. 7-31, jan./jul. 1993.

. Ciencia y feminismo. Madrid: Morata, 1996. (Colección Psicología Manuales)

KERGOAT, Danièle. "Dinâmica e consubstancialidade das relações sociais". Novos Estudos -CEBRAP, n. 86, p. 93103, mar. 2010.

LATOUR, Bruno; WOOLGAR, Steve. A vida de laboratório - a produção dos fatos científicos. Rio de Janeiro: Relume Dumará, 1997. 
LATOUR, Bruno. Ciência em ação - como seguir cientistas e engenheiros sociedade afora. São Paulo: UNESP, 2000.

MACIEL, Betania. "Mulheres cientistas: a afirmação da diferença?". In: VII JORNADAS DE FILOSOFIA/I CONGRESO INTERNACIONAL SOBRE CIÊNCIA E SOCIEDADE, 1999 Valladolid. Valladolid: Universidad de Valladolid, 1999.

MAPA de investimentos do CNPq. Brasil. Projetos e Bolsas em vigência, 2014. Disponível em: http://efomento.cnpq.br/ efomento/distribuicaoGeografica/distribuicaoGeografica. do?metodo = apresentar.

MATIAS DOS SANTOS, Vívian. "As origens do processo de marginalização das mulheres na ciência: uma análise das influências culturais nas teorias que legitimaram uma educação desigual entre os sexos". Emancipação, v. 1, p. 69-96, 2006.

. Mulheres e homens na política de ciência e tecnologia. Fortaleza: UECE/Edmeta, 2012.

MELO, Hildete Pereira; LASTRES, Helena Maria M. "Ciência e Tecnologia numa perspectiva de gênero: o caso CNPq". Centro Brasileiro de Pesquisas Físicas, 2006. p. 1-27.

OSADA, Neide Mayumi; COSTA, Maria Conceição. "A construção social de gênero na Biologia: preconceitos e obstáculos na biologia molecular". Cadernos Pagu, Campinas, $\mathrm{n}$. 27, p. 279-299, jul./dez. 2006.

PATEMAN, Carole. O Contrato Sexual. São Paulo/Rio de Janeiro: Paz e Terra, 1993.

PEIRANO, Mariza G. S. "Os antropólogos e suas linhagens". In: PEIRANO, Mariza G. S. A favor da etnografia. Rio de Janeiro: Relume Dumará, 1995. p. 13-30.

PISCITELLI, Adriana. "Interseccionalidades, categorias de articulação e experiências de migrantes brasileiras". Sociedade e Cultura, v. 11, n. 2, p. 263-274, jul/dez. 2008.

PUGLIESE, Gabriel. "Um sobrevôo no "Caso Marie Curie": um experimento de antropologia, gênero e ciência". Revista de Antropologia, São Paulo, v. 50, n. 1, p. 347-385, jan./jun. 2007.

ROCHA-COUTINHO, Maria Lúcia. "Variações sobre um antigo tema: a maternidade para mulheres com uma carreira profissional bem-sucedida". In: FERES-CARNEIRO, Terezinha [Org.]. Família e casal: efeitos da contemporaneidade. Rio de Janeiro: PUC, 2005. p. 122-137.

ROUDINESCO, Elisabeth. A família em desordem. Rio de Janeiro: Jorge Zahar, 2003.

SANTOS, Boaventura de Sousa. "Da sociologia da ciência à política científica". Revista Crítica de Ciências Sociais, n. 1, p. 11-56, jun. 1978.

. "Para além do pensamento abissal-Das linhas globais a uma ecologia dos saberes". Novos estudos, n. 79, p. 71 94, nov. 2007. 
"Para uma sociologia das ausências e uma sociologia das emergências". In: SANTOS, Boaventura de Sousa. Conhecimento Prudente para uma vida decente - Um discurso sobre as ciências 'revisitado'. São Paulo: Cortez, 2006. p. 777-821.

. Um discurso sobre as ciências. São Paulo: Cortez, 2005.

SARDENBERG, Cecília Maria Bacellar. "Da crítica feminista à ciência a uma ciência feminista?". In: COSTA, Ana Alice Alcântara; SARDENBERG, Cecília Maria Bacellar (Orgs.). Feminismo, Ciência e Tecnologia. Salvador: REDOR/NEIMFFCH/UFBA, 2002. p. 89-120.

SCHIENBINGER, Londa. O feminismo mudou a ciência? Bauru: EDUSC, 2001.

[Recebido em 06/05/2015, reapresentado em 05/01/2016 e aceito para publicação em 13/04/2016]

\begin{abstract}
A "Partial Perspective" about Being a Woman, Scientist and Northeastern in Brazil Abstract: This paper proposes to understand how women scientists are embedded in the production of scientific and technological knowledge in specific federal public universities in the Northeast of Brazil. The interviews and direct observations in daily life scientific work made possible the construction of reflections grounded on the social experiences of women scientists belonging to two knowledge's branches: humanities and supposed "hard sciences". Through this partial and situated approach, about insertion and permanence of women in contemporary science, we could observe the conservation of old issues that remain as important for feminist and gender studies of science.
\end{abstract}

Key words: Women Scientists; Gender; Science.

824 Estudos Feministas, Florianópolis, 24(3): 801-824, setembro-dezembro/2016 